\title{
Study on Model-driven ERP System Implementation for Textile Enterprises
}

\author{
Sun Ling ${ }^{\mathrm{a}}$, Pan HaiXia ${ }^{\mathrm{b}}$ \\ ${ }^{a}$ Institute of Textile, Tianjin Polytechnic University, Tianjin, China \\ ${ }^{b}$ Collage of Software, Beihang University, Beijing, China
}

\begin{abstract}
To deal with some problems of ERP software for textile enterprises, such as immaturity, poor adaptability to business management model and difficulties in meeting enterprise requirements, this article proposes an ERP system implementation method using MDA(Model-Driven Architecture)concept and the method has been in full application in textile enterprises. Such method may provide customized ERP system quickly based on specific information management requirements. It may vary with the change of management requirements in an economic, cost-effective and fast way.
\end{abstract}

Index Terms: Model-driven Architecture, BL platform, textile enterprise, ERP implementation

(C) 2011 Published by MECS Publisher. Selection and/or peer review under responsibility of the International Conference on E-Business System and Education Technology

\section{Introduction}

With regard to the information technology application in textile enterprises, only about $7 \%$ of the enterprises (according to sampling survey by China National Textile and Apparel Council in 2007) are using ERP (Enterprise Resource Planning) software, an IT product that features most industry characteristics and is extensively developed and perfected. Most enterprises are still using outdated manual management.

Reasons:

1) As a traditional labor-intensive industry, textile industry is unique in information technology construction. More than $99 \%$ of textile enterprises are small and medium-sized enterprises. The industrial chain is long, covering the entire chain from fiber to final product (apparel, household textile products and industrial textile products). It also involves a number of related industries, such as planting, textile machinery, etc. Each segment of the industry has unique characteristics and differentiated demands.

2) Currently ERP(Enterprise Resources Planning) software for textile enterprises is immature. ERP system application does not suit business management model and it is difficult to meet enterprise requirements. These are the bottlenecks of ERP application in textile enterprises.

Corresponding author:

| E-mail address: ${ }^{\mathrm{a}}$ sunling@ cpittex.com; ${ }^{\mathrm{b}}$ jianghomgbj@msn.com 
To deal with these matters, this article proposes an ERP system implementation method using MDA concept. Such a method may provide customized ERP system quickly based on specific information management requirements. It may vary with the change of management requirements in an economical, cost-effective and fast way.

\section{Basic Concept of MDA and Model-Driven ERP Implementation}

MDA is a software development framework proposed by Object Management Group (OMG). The framework is based on UML(Unified Modeling Language) and other industrial standards, supporting visualization, storage and exchange of software design and model. Its concept is to separate the standard of system operation from the methods and details of system capability of utilizing the bottom layer platform, providing an approach (through relevant tools) to standardize an independent system and standard platform. It chooses a specific implementation platform for the system and transfer system standards onto the specific implementation platform. To make it short, MDA uses the model of system to generate the structure of system.

The three main goals of MDA are to realize portability, interoperability and reusability through the separation of structure. MDA complies with a series of open industrial standards, such as Unified Modeling Language (UML), Extensible Markup Language (XML), Common Object Request Broker Architecture (CORBA), etc.

MDA modeling is based on functions instead of specific language, platform or implementation technology. The model normally uses graphics and texts to describe a system and its environment. It may simplify system integration, reduce development cycle and save enterprise resources. Its advantages include high-efficiency implementation of system integration, interoperability, solution for legacy system issues, adaptability for the fast changing Business Logic (BL), reduced development cycle, etc.

Model-driven method is to guide system design, development and maintenance with a model. Successful cases of model-driven ERP implementation include World Wide Web and Hyper Text Mark-up Language. They use markup language to describe static display content. The following features are realized for content display:

1) Client does not need to update software and Web server is standard software;

2) No need of sophisticated programming and the content of website can be individualized and changed anytime;

3) Remote maintenance can be done via Internet. See Fig. 1 and Fig. 2.

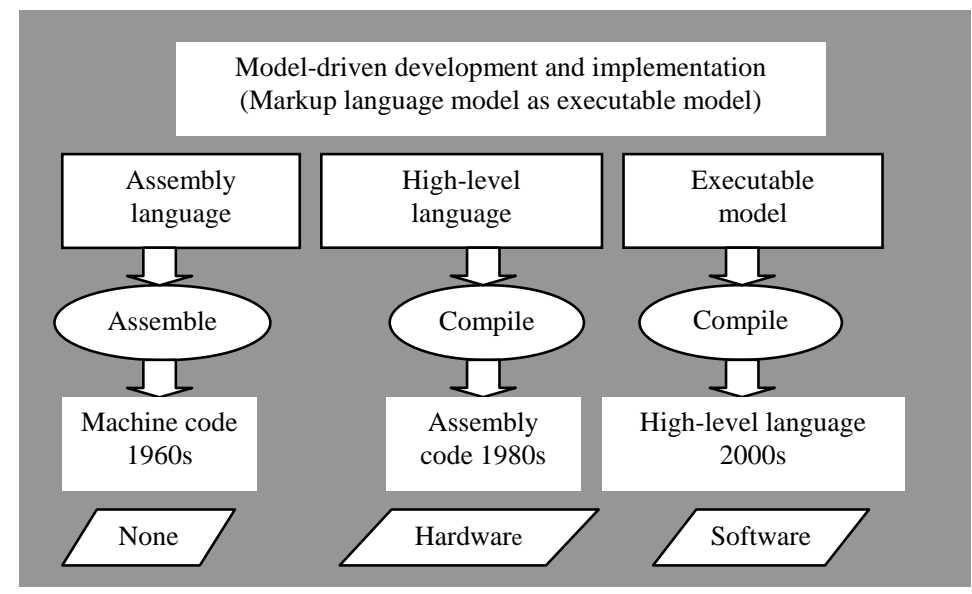

Fig. 1. MDA Distilled: Principles of Model-Driven Architecture 


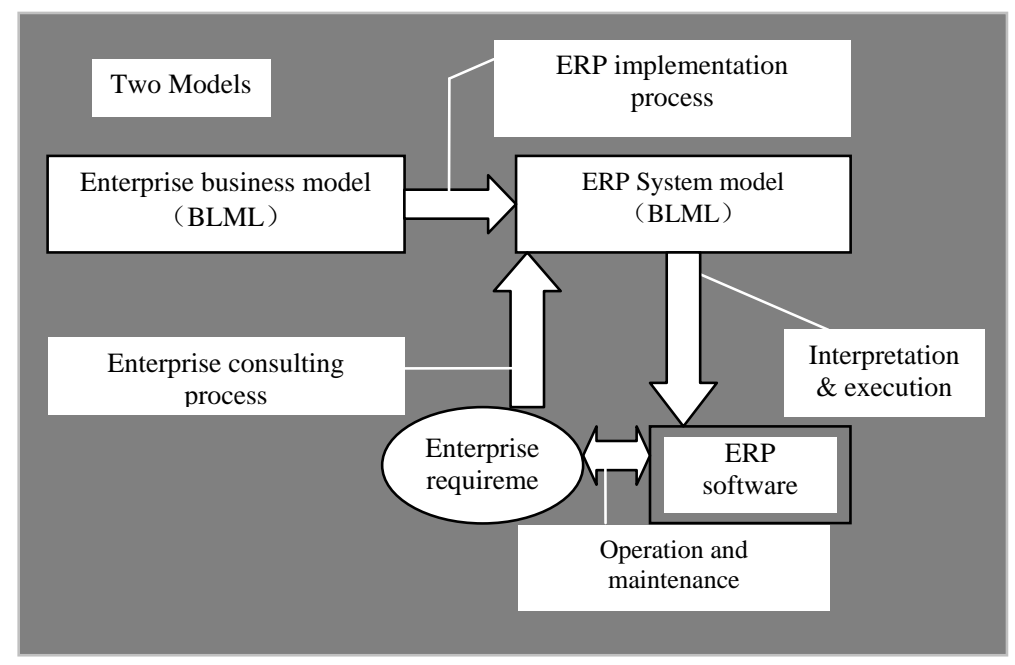

Fig. 2. Creation and conversion of model

\section{Basic Principles of BL Platform System and Implementation BLERP}

Business Logic (BL) is not a stiff ERP system or an application software development environment. It is an ERP system structuring platform capable of fast customized development based on specific information management requirements.

\subsection{Basic principles of BL platform system}

Categorize and abstract the complex and diversified data and information process requirements of the enterprise, and realize the constant common features. Then construct an ERP system based on specific enterprise model. Therefore, constructing ERP system on BL platform is a process from the abstract to the concrete.

Explained in detail as below:

1) BL platform includes abstract functions of ERP software system. These abstract functions can be used to create concrete software functions together with enterprise model.

The real world is very complex and our knowledge of the world and ability to transform it are based on our two most powerful logics - deduction from concrete to abstract and induction from abstract to concrete. Although ERP system has large scale and diversified functions, there are still underlying rules. As a computer software system, it is no more than data input, processing and output. These three functions are the utmost abstract of all computer software functions. For ERP system, sure it has more specific data input, processing and output modes. BL system utilizes this principle to abstract the functions of ERP system into limited number of abstract classes and creates software functions of these abstract classes. Then establish specific ERP functions according to enterprise requirements (no need of programming during this step).

2) In BL system, enterprise model is an individualized model to describe the structural requirements of enterprise ERP system. The model is generated by BL enterprise modeling platform with XML (Extensible Markup Language) text structure and can be combined with BL operation platform to establish an ERP system quickly. Enterprise model is a tool that describes enterprise requirements using XML structural text 
format. It is a model that configures ERP abstract functions in specific and organizes these specific functions to construct a total solution that describes enterprise requirements. Enterprise model and BL operation platform are integrated together dynamically.

BL operation platform only includes the abstract functions that understand enterprise model and does not include any processing method, content or management thought of the enterprise or business. Such processing method, content and management thought are described within enterprise model. Therefore, the construction of specific enterprise ERP system is the construction of enterprise model that describes specific enterprise business and management process mode.

3) BL platform includes "System Operation Platform", "Enterprise Modeling Platform" and "System Administration Platform". See Fig. 3 - BL for platform software structure diagram.

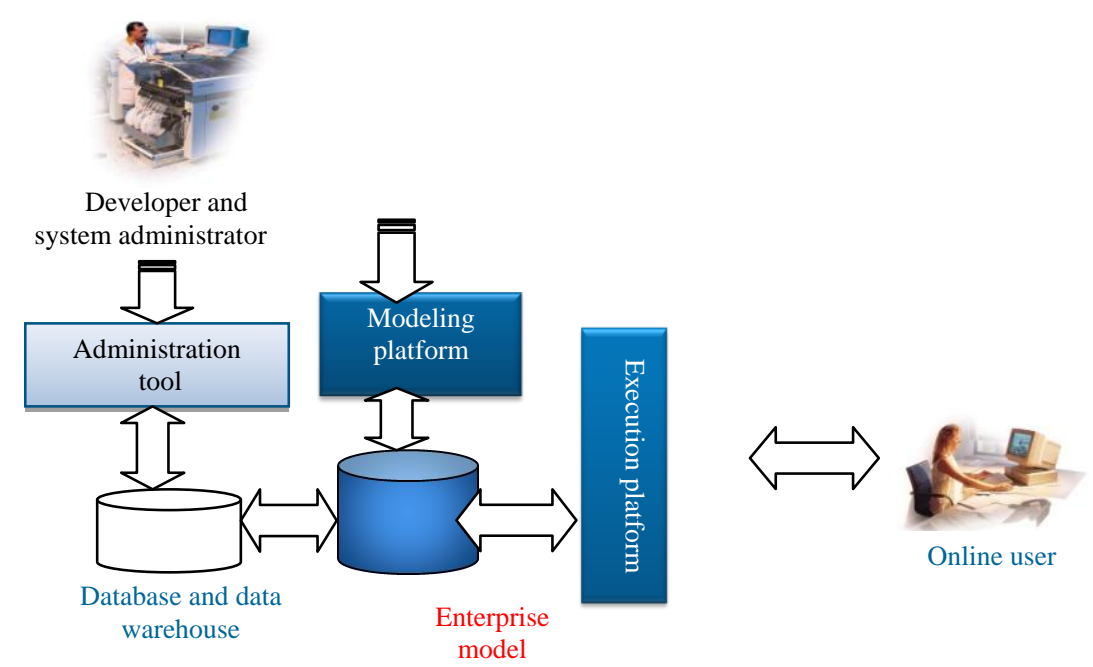

Fig. 3. BL platform software structure diagram

BLML and model:

- Reference relationship between entities

- <ATTENDEE CODECOL="c_gsdn_ecode" ERI=".GSDN.ATTENDEE" ACTION="DEFAULT" ATTCODE="ecode" AUTOFRESH="FALSE" MULTISELECT="FALSE">

- <DATACOL CODE="C1" COL="c_gsdn_ename" DSINDEX="1" ATTVALUE="[ename]"/>

- $<$ DATACOL CODE="C2" COL="gsid" DSINDEX="1" ATTVALUE="[gsid]"/>

- </ATTENDEE>

- Calculation relationship between items

- <COMPUTER DESTCOL="ywdj">

- $\quad<$ SOURCECOL CODE="C1" COLCODE="ywhsdj" DSINDEX="2" VALUE="1"/>

- <SOURCECOL CODE="C2" COLCODE="ywslv" DSINDEX="2" VALUE="1"/>

- <EXPRESSION> [ywhsdj]/([ywslv]+1)</EXPRESSION>

- </COMPUTER> 
Implementation flow and features of BLERP - the implementation process of BLERP is actually the integration of industry experience and individual requirements of the enterprise. The implementation process includes:

1) System planning (defining project scope and resource allocation);

2) Requirements analysis and design (determining system functions and data structure);

3) System implementation (create and correct BL model);

4) System installation training and run-in;

5) System maintenance (remote upgrade via Internet).

The implementation flow is tailor-made, highly efficient, to changing requirements and can be maintained remotely in real-time. Customizing enterprise ERP implementation through "Business Logic Implementation Platform" using MDA concept has been applied to some printing/dyeing and wool spinning enterprises. This article gives an overview of Printing \& Dyeing Enterprise Resource Planning (PDERP) and verifies the features of Business Logic ERP system implementation platform, such as adaptability, high-efficiency and fast remote maintenance.

\section{Printing \& Dyeing Enterprise Resource Planning (PDERP) Overview}

\subsection{Business Model of Dyeing Factory}

1) The factor centers on customers and orders to determine product variety, control inventory, plan process, formulate plan and control operation.

2) Managers and merchandisers need to follow up the production process in real-time and master production schedule and quality information timely.

3) Management level is the key to ensure quality, improve yield and reduce cost. Requirement on information share is demanding during the sourcing, delivering and using of information. (Order, process, plan, operation, final inspection and shipment make up a complete information chain.)

\subsection{Information Management Issue of Dyeing Factory}

1) Completed and integrated information technology management tools are required throughout the entire business process.

2) Information management shall be based on the principles of enhancing business transaction and management efficiency of the staff and reducing cost.

3) Information management can be gradually extended with the change of production and improvement of management level.

\subsection{ERP System Goal of Dyeing Factory:}

Improving the efficiency of corporate operation, sorting out procedures and enhancing enterprise competitiveness are goals.

\subsection{ERP System Function of Dyeing Factory:}

Forms or statements of signing contract, purchasing raw material, proofing, production process, automatic generation of flow card, scheduling, process barcode statistic, finished product warehousing, quality management, hardware \& dye material inventory and shipment \& settlement and handled by computers. Accuracy and efficiency are several times of conventional transaction. 
Effective production mode is centered on orders and plans. In conventional production mode, the subsequent production plan is based on the actual production of workshop. PDERP emphasizes plan-driven production mode. If the plan was not followed, workshop production may have problem. With PDERP, the plan can be accurate to each shift, dye vat, process or machine.

Barcode production statistic feature gives the performance of production plan in real-time and the implementation condition of a task at a certain process or machine. Once the worker has finished a given task at a given process, information such as task, process, machine, station, etc. is scanned into the system via barcode. Managers and business personnel may acquire production status and task performance in real-time.

Piecework wage of workers can be calculated anytime.

Comprehensive color proofing and process \& concoction management may reduce error of technical parameters during production. Color process sheet is generated during proofing and production process is formulated by technical department based on customer's model. These two process data are corresponding to customer's model and specific order. These programs are controlled by the system to provide production plan task and are used for planning. No transcription is required, thus reducing human error.

Optimized planning - Processing sequence can be optimized according to machine and color depth of the task.

Enhance equipment capacity factor and processing quality - Higher efficiency and dyeing quality and lower dyeing cost.

Dye \& hardware material management feature gives dyeing cost in real-time. Direct and indirect costs such as dye material, additive, energy, labor, etc. can be accurately audited.

Advanced and flexible access management - Personnel with different permission will see and use different functions. It not only ensures data security, but also simplifies the use.

Protection of enterprise information assets - Buildup of experience and knowledge of the enterprise is less dependent on individuals.

Experience and knowledge such as customer information, process data and business record are intangible assets of an enterprise, and are crucial to the sustainable and stable development of the enterprise. However, these resources may flow away from the enterprise as a result of staff turnover. PDERP helps enterprises accumulate information and knowledge assets continuously. Strict access and flow management guarantees that the right information is given to right person, ensuring data security.

The system will grow alongside the development of enterprise with remote Internet upgrade \& maintenance capability. PDERP system has excellent architecture. New services can be added without the need of program development. Form items can be modified, statement form can be configured and logic relationship among data can be changed, offering great flexibility. Therefore, enterprise growth will enrich the functions of PDERP instead of becoming a restriction of the enterprise like other software.

Web Service technology is the foundation of distributed computing. The system can be used or developed remotely via Internet.

\section{Conclusions}

BLERP system development platform established with the concept of model-guided system design, development and maintenance has realized the following benefits in the ERP implementation of textile enterprises: It is tailor-made to specific enterprise requirements and may vary with the change of management requirements in an economical, cost-effective and fast way.

\section{Acknowledgements}

I wish to thank Dr. Jiang Hong and Dr.Pan HaiXia for their help and efforts completing this paper. 


\section{References}

[1] Jiang Hong, Business Logic (BL) ERP System Construction Platform Introduction, Tianjin Chuanghua Weiye Technology Development Co., Ltd., 2008 “(姜宏, Business Logic (BL) ERP 系统构建平台简 介，天津创华伟业科技发展有限公司，2008.)”

[2] Stephen J. Mellor, Kendall Scott, Axel Uhl, Dirk Weise, MDA Distilled: Principles of Model-Driven Architecture, Addison-Wesley, 2004

[3] (US)Thomas Stahl;Markus Voelter, Model-Driven Software Development: Technology, Engineering, Management, Wiley, 2009 